\title{
Erratum
}

\section{A Computer Algebra Primer and Homework Exercises for use in an Intermediate Macroeconomics Course - A Student/Teacher Collaboration}

\section{LUKE OLSON, MAX JERRELL and RYDER DELOLOYE} Northern Arizona University Flagstaff, AZ 86011, USA

E-mail:1mo@nau.edu,max.jerrell@nau.edu,hrd@nau.edu

Accepted 24 October 2005

Unfortunately the page numbers online for this article are incorrect. The correct page numbers should be: 233-240. 